\title{
1 Critical realism as a social ontology for economics Jamie Morgan*
}

\subsection{INTRODUCTION}

In the editor's introduction to Ontology and Economics (2009, pp. 1-3) Edward Fullbrook makes the point that Tony Lawson $(1997,2003)$ has changed the nature of the 'conversation' regarding economic methodology. Specifically he has made the issue of social ontology a central one. Lawson's work along with that of a number of other proponents of critical realism has important implications for economics (Fleetwood 1999; Lewis 2004). The focus on social ontology in critical realism puts forward a position based on causal powers inhering in entities (such as structures and agents), complex interactions between causal powers in terms of arising events, and a consequent account of systems as 'open'. According to its proponents, this social ontology is implicit within heterodox economic positions but is antithetical to mainstream economics. This is because mainstream economics pursues theorizations and applications that reduce to closed systems and typically assume and/or explore event regularities, often based on uses of mathematical models that are expressed in a deductive form. Critical realism's great strength is that it provides a more plausibly realistic account of the economy as an intrinsic aspect of society; in so doing it 'under-labours' for heterodox approaches. However, insofar as it only underlabours, critical realism can also be developed in a variety of ways that are consistent with its approach to social ontology. This extends also to issues of method and methodology (e.g., Downward 2003; Carter and New 2004). This chapter provides an introductory account of the core elements of a generic critical realist social ontology for economics based on the development of critical realism within the philosophy of science and of social theory originating with Roy Bhaskar and a number of others (Bhaskar 1975, 1979; Harré and Madden 1976).

\subsection{WHY SOCIAL ONTOLOGY SHOULD MATTER}

Taken in isolation the following can seem a ridiculous statement; ridiculous in the sense that it is so obvious it ought not to require such statement: Any science, including a social science such as economics, ought to be about reality, the nature of reality ought to make a difference to how we study it and what we then claim about it as a form of knowledge.

However, when one considers that knowledge is a social product then the need to be reminded of the significance of the obvious becomes considerably less ridiculous. Knowledge is a set of claims based on particular theories, and particular investigations, using particular methods. These develop over time. They become a set of resources to draw upon, but are more than this. They are components in knowledge organizations, such as disciplinary departments in universities. One learns how to do things in recognized ways and these provide accepted practice. One realizes that some ways of doing things 
have attractive characteristics, and these may be of many kinds. There may be puzzles to solve and lacunae to investigate; an approach might carry a certain difficulty or apparent complexity within it that creates status through mastery; an approach might carry an external status significance - it seems analogous to what is done in other disciplines that already have status, such as physics, and it might have the attractiveness of simplicity as a tool for policy advice or for policy 'evidence'. It may attract funding. Careers are created and ways of doing things can be reproduced and augmented, becoming dominant. Those who reproduce them come to accept them and can do so non-reflexively as simply how things are done, the best we have, or more cynically, as profoundly flawed but part of the game we play to get on. The process of reproduction can then also create prejudice and foster exclusions and marginalizations that serve to simply eliminate whole frames of reference, and with them possibilities of viewing the world differently (a 'that's not what we do' that prevents things from being seen or understood). A status quo can be reinforced because power (benign or otherwise) is intrinsic to the processes of knowledge as a social product.

The point, then, is that it is not inexplicable that a discipline develops in ways that lose touch with the basic statement of the obvious given above. Ways of doing things become 'locked-in', seemingly 'better' arguments in terms of recognized reality need not win out, and a discipline can become focused in terms of developing characteristics (technical skills, the puzzles of a theory or a model form) that are not all directed in any primary sense towards investigating reality. At the same time, a discipline can be developing whilst still notionally adhering to the idea that it does investigate reality, or contribute to our understanding of it at some level, but can fail to actually exhibit that commitment. It can fail to maintain a critical check on how knowledge is produced: the significance of the use of assumptions, the value of ways of theorizing, and of given theories and models; that is, it can fail to place a critical check on the common trajectory of the field. And it can fail to address persistent failures: the failure to produce consistent and coherent types of knowledge, able to fulfil the goals set by its own adherents for how knowledge is to be adjudicated (such as the derivation of significant laws or predictive power); and, more profoundly, the failure to provide widely accepted meaningful insight into reality (recognizable explanatory success in regard of the key phenomena of the field).

It is not, of course, just explicable that a discipline can lose touch with the basic statement of the obvious above. In the case of economics it is a widely acknowledged issue. The issue is not new but the role of economics in the global financial crisis has brought the issue to the fore. There is a widespread dissatisfaction with the state of economics, and not least amongst its students. If you recognize the general problems above as specific to economics then you are by inclination, if not yet self-identification, a heterodox economist. If you see only minor cause for concern, the chances are you are a mainstream economist.

Now, consider the significance of what I have said so far. Knowledge is a social product, and can for various reasons lose sight of or become deformed in terms of its primary concern: the investigation of reality. This creates a warrant for some form of check or critical framework of analysis of knowledge as a social product. In order to keep a discipline honest it would benefit from a domain of argument that challenges that discipline in terms of its commitments or goals (such as seeking laws or formulating predictions) as well as its ongoing explanatory success in relation to its ways of theorizing, 
and its use of methods. This critique needs a general domain within which it can engage the identified issues, and traditionally this is the realm of philosophy in the form of meta-physics. However, the revival since the 1970s of a concern with this general domain in relation to the social sciences has used the term 'ontology' or 'social ontology'. An ontology is a theory of being. It starts from the question, 'What must be the case for $\mathrm{x}$ ?' in order to build up, using varieties of evidence and argument, a general set of claimed characteristics of reality in some context. Note, however, that the initial justification for the importance of ontology is not a specific ontology, it is the value of explicitly addressing key issues of general critique of a discipline, such as economics, in terms of their realism because these can easily be neglected by that discipline.

Social ontology then is an invitation to consider general aspects of knowledge in terms of critique. However, for that critique to be meaningful, one assumption and a further claim are required. The assumption (though one might state this more assertively as a warranted insight) is that all theories and ways of investigating the world involve at least an implicit ontology; that is, what the world must be like for the approach to be appropriate, fruitful, successful and so forth. The further claim is that for critique within social ontology to be feasible and constructive (rather than merely disruptive and destructive) the critique requires an explicit ontology as a point of comparison with any theory and way of investigating the world.

Here, the transition to a substantive ontology as a resource has sometimes caused unease amongst economists. It can appear as though a fixed prior or 'foundational' body of theory, smuggled in as a 'here is reality', is simply being imposed upon the field as a standard to which all else must conform. The impression can be given that this is imperialism for economics, as problematic in its own way as economics imperialism. There are two relevant responses here. First, as an invitation to consider general aspects of knowledge in terms of critique, social ontology is intended as a dialogue within a domain of argument. In this sense, proponents of social ontology are merely claiming that it is important not to neglect this domain of argument, since it provides one (not the only) appropriate arena for dialogue. There is no assumption in modern philosophy that foundationalism is tenable. Second, a substantive ontology need not be 'news from nowhere'. For example, the one that is set out in the next section, commonly termed critical realism (though various other terms have been applied), ${ }^{1}$ derives from engagement with recognized problems of fields of study. It is not a form of rationalism, where an isolated philosopher explores the content of their own mind in search of indisputable truths. It is a response to tensions in knowledge claims and pre-existing disciplinary and philosophical positions that seek to justify or shape those knowledge claims. As such, it is a collection of general claims regarding reality - an ontology - derived from the analysis of problem sets (conceptual and/or evidential). The general question form, 'What must be the case for $\mathrm{x}$ ?' is a conditional one where the 'must' arises from argument and can be disputed. It follows then that a substantive social ontology is no more fixed or immune to critique or change than any other body of theory. In practice, to a large degree the process of critique is the source of a social ontology. So it further follows that, based on the ontological implications of problems and failures, the development of a given social ontology can provide more than critique only.

Ultimately, social ontology should matter because the combination of critique in a domain of argument and of a substantive ontology, derived from recognized problems, 
provides a multifaceted 'under-labouring' service for any particular field of study. In so doing it can provide a ready response to two forms of scepticism regarding ontology. First, the often-heard comment that this is just philosophy and I have actual economics to get on with. This position is no more tenable than the modern neglect of the history of economic thought or of pluralism in economics. It leads directly to practitioners falling short in terms of the statement of the obvious that this section began with. Second, the sometimes-heard comment that an economist's approach already has a fully formed philosophical position or perspective or worldview, and does not require another one. An explicit social ontology is not necessarily some alien artefact. Substantive social ontology derives from problem sets and can provide a constructive generalization of commonalities between disciplinary approaches or schools of thought, as well as a focus on differences and potential problems. Here, various issues can be reconsidered from new perspectives. Social ontology challenges us to consider our commitments and provides constructive yet contingent insights for theory and practice. ${ }^{2}$ With this in mind I now set out the key concepts for a critical realist social ontology. I say 'for' because the best way to set out the line of reasoning by which the social ontology is constructed is to briefly begin from issues arising in terms of natural science. This provides clarity and prevents misunderstanding.

\subsection{KEY CONCEPTS FOR A CRITICAL REALIST SOCIAL ONTOLOGY}

\section{Philosophy and the Epistemic Fallacy}

Critical realism emerged in response to a core problem in the philosophy of science. ${ }^{3}$ Empiricism, the claim that all knowledge is derived from sense experience, and then positivism, the claim that knowledge can be developed or refined according to particular strict criteria, had resulted in an approach to science that focuses on the product of scientific practice (the statement of laws) and on forms of testing for the validity of laws (in general, verification and confirmation, subject to the hypothetico-deductive model or the inductive-probabilistic model). Popper's falsification reversed the significance of testing but maintained the same focus on the product (the statement of laws). A number of philosophers, most notably Rom Harré and Roy Bhaskar, began to question this focus in the 1970s. A stated law remains always contingent because knowledge is fallible. Testing criteria seek to express the certainty of that law and thus cannot fulfil the function for which they are devised. Moreover, it requires particular conditions to observe or express the law, and these are often artificial, constructed by the scientist. This led Bhaskar to ask: what is it that makes science, including the work that leads to the statement of laws, manifestly fruitful and yet also incomplete? More specifically, what is it about the nature of reality that makes laboratory experiment necessary in order to express some forms of law-like activity? The scientist is not simply producing arbitrary activity, they are isolating aspects of a more complex reality to observe particularized relations and effects.

For Harré and for Bhaskar, positivism had misunderstood the practice of science and the significance of this practice, and in so doing it had produced a false understanding, affecting how we think about the significance of knowledge in terms of reality. The 
emphasis had been placed on the statement of the laws, and the test of the laws, focused around their repeated expression as outcomes. Laws were thus expressed as 'constant conjunctions' of the form 'whenever $\mathrm{x}$ then $\mathrm{y}$ ', observed in events. But any observation of reality tells us that one rarely encounters this kind of regularity in events. It typically requires intervention in order to produce the conditions for regularity. Positivism, therefore, had set up an impossible measure of knowledge for science. It had done so by seeking something that would not typically be found in reality, even though the underlying activity being investigated, properly conceived, remained insightful and important (we are capable of manipulating the world based on the understanding of principles). According to Bhaskar, positivism had committed an 'epistemic fallacy'; it had confused an issue of ontology or the nature of reality with an issue of epistemology or the nature of how we can know something about reality. Bhaskar essentially argued that by investigating the failure of the epistemology in the light of scientific practice one could infer something about the nature of reality in terms of which the failure had occurred. Harré made the case that what science was investigating was the powers of entities that are then expressed in complex ways, and Bhaskar developed this focus to make the ontological case that reality has 'depth'.

\section{Depth Realism}

One can make sense of Table 1.1 in the following way. ${ }^{4}$ Time does not stop and we live in a continual flow of events. However, we can pause to consider that flow of events. The first thing to note is that not everything that occurs is experienced. As such, experience is a subset of events that occur. The flow of events, moreover, is a series of expressions of what could have occurred. Until they occur, events are merely potential outcomes. For them to be potential there must be something that can give rise to the event, and this is the powers or capacities of entities and structuring processes. The multiplicity of powers or capacities of entities, and of a mix of different entities, can be conceptualized as generative mechanisms or structuring processes that cause things to occur as events. One can, therefore, make sense of a reality that we experience as relatively stable much of the time, and in which we are able to knowingly intervene to attempt to manifest given outcomes. Events may rarely be regular (in the 'whenever $\mathrm{x}$ then y' sense of a constant conjunction) but they are not thereby, when properly understood, uncaused or simply arbitrary.

Consider this in terms of laboratory experiment. Laboratory experiment creates controlled situations in which given entities are deliberately isolated in order to express particular powers as events to be observed (often with the aid of technological

\section{Table 1.1 Depth realism}

\begin{tabular}{llll}
\hline $\begin{array}{l}\text { Domains } \Rightarrow \\
\text { Related distinctions }\end{array}$ & Real & Actual & Empirical \\
$\Downarrow$ & & & \\
\hline Mechanism & $\bullet$ & $\bullet$ & \\
Event & $\bullet$ & $\bullet$ & $\bullet$ \\
Experience & $\bullet$ & $\bullet$ & \\
\hline
\end{tabular}


augmentation). Laboratory experiment is a deliberate bringing together of experience, event, and generative mechanism. That the three can be brought together is a strong indication that there are structured entities and structuring processes with powers. Moreover, the necessity of intervention to align the three and express an isolated relation of causation is also a strong indication that there is more to reality than the isolation might imply. It is then also a strong indication that it is an error to conflate experience, event and generative mechanism, as an always experienced and definite outcome, as though that is a sufficient conception of reality - a constant conjunction merely because the three can be brought together. ${ }^{5}$ In order to avoid this conflation, critical realism then distinguishes three domains of reality. There is an empirical domain of what is experienced, and this is a subset of the actual or what occurs as events, and this is an expression of what could occur based on the powers or capacities of relevant entities operating as generative mechanisms in complex ways. Note here that the empirical and the actual are also real. The distinction is between domains of reality. The distinction is to prevent a conflation and to allow further consideration of the ways in which each may be real. For example, experience may be real in the sense that it occurs for people and has consequences for their conduct thereafter, but it is not necessarily a true or complete account of given events. This brings us to a further distinction.

\section{The Stratification of Reality and Emergence}

The example of laboratory science has been used to make the initial ontological distinction between experience, events and generative mechanisms. Clearly, there are many kinds of scientific practice and many subject domains of natural science, such as physics, chemistry, and biology, as well as of social science. This creates the further issue of in what sense each refers to a different aspect of reality. According to critical realism, reality has both depth and strata. Strata refer to the possible order of aspects of reality, and stratification is a claim that is contingent on the findings of science. Physics investigates the basic principles of relation of energy and particles, chemistry investigates the properties of combinations of particular atoms and molecules, biology investigates aspects of organic life and so on. A biological entity cannot exist without atoms or molecules, and atoms or molecules are constituted on the basis of relations of energy and particles. Each then would seem to refer to a more basic aspect of reality. However, it does not thereby follow that any given aspect can be reduced to another. A biological entity does not break principles of chemistry since it is chemically constituted, and nor does it break laws of physics. However, one cannot explore all significant aspects of biology in terms of chemistry or physics without doing violence to our understanding of biological entities. For example, the behaviour of a cow is not solely describable as a process of digestion of grass, nor of the energy exchange of mitochondria within processes rooted in the laws of thermodynamics. This insight then leads to the concept of emergence.

Emergence is the concept that there are powers, capacities, or identifiable features of given specifiable entities that cannot be reduced to the powers and capacities of their parts. Rather, the arrangement of the parts creates further emergent properties that only exist insofar as the arrangement continues. Clearly, there is a great deal of scope here for debate concerning what is a specifiable emergent entity, since any given emergent entity 
could also then be considered a part of a greater whole. However, insofar as emergence is a defensible concept, then the issue is one of empirical dispute (the identification of non-reducible powers and so forth). The key point remains that in order to prevent what seems an empirically untenable reduction of all entities to some primary unit that fully accounts for all aspects of properties and causal processes, a genuine whole must be more than simply an epiphenomena of the parts.

It should also be clear here that the concept of strata and that of emergence provide further conceptual insight when thinking about the significance of depth reality. Insofar as events occur, then aspects of many generative mechanisms of different emergent entities may be involved, and, concomitantly, powers may be exercised or expressed that can be investigated in terms of different strata. The concepts of strata and of emergence can be used to focus on different aspects of events because they allow us to consider different generative mechanisms and to do so in different ways. This returns us to the point that emergent entities are not 'breaking' laws identifiable in terms of different strata, they are acting according to particular powers and capacities that may also be conditioned by different strata. The multiplicity and complexity here would seem to be an important reason why the reality we experience is not regular in a constant conjunction sense, and this brings us to the concept of an open system. This is a concept best introduced via the problem of closed systems.

\section{Closed and Open Systems}

From a critical realist perspective, the major identified error in positivism is that it tacitly assumes an automatic and continued coincidence of a given individual generative mechanism, events expressing that mechanism, and our experience of them. In so doing it commits an epistemic fallacy. By seeking constant conjunctions in events, which can be stated as significant laws, it makes constant conjunctions the necessary measure of adequate knowledge. This focus then becomes the core of an implicit ontology and the question can then be asked: what kind of reality would make this approach to knowledge appropriate or successful? This brings us back to the coincidence of isolated mechanisms and events that can then be observed. For such a situation to pertain then a system must be 'closed'. It must exhibit an 'intrinsic' closure, that is, the given event y must always follow from the mechanism $x$; and it must exhibit an 'extrinsic' closure, that is, the system must be separated from external influences that would affect the intrinsic closure, and that would create irregularity.

To be clear, the point being made here is that reality would have to be intrinsically and extrinsically closed for a constant conjunction focus to be adequate (sufficient to fully explore the nature of reality). A reality of this kind would be one where there could be neither irregularity in events or the possibility of genuine change. It would be 'atomistic': that is, involving the repetitive association of $\mathrm{x}$ and $\mathrm{y}$ in isolation. If one tried to imagine such a reality, it would be one of individualized systems reduced to hermetically sealed permanently cycling sets of separated $\mathrm{x}$ and $\mathrm{y}$ relations. It would be a multiplicity of non-interactive monads. Clearly, no one would attempt to defend such a position regarding reality, and as such one might think a straw man was being constructed here. This, however, is not the case. The ontological implications are an unintended consequence of the epistemological focus. Recall that the original warrant for a focus on ontology was 


\section{Handbook of research methods and applications in heterodox economics}

the argument that approaches to knowledge can lose sight of the core issue of realism in various ways.

A discipline, for example, can develop whilst still notionally adhering to the idea that it does investigate reality in some sense, and yet fail to do so adequately because it does not recognize or address its basic problems of realism, and this may be precisely because the discipline continues to be shaped by a problematic philosophy of science. A discipline strongly influenced by positivism, for example, might attempt to adapt its knowledge claims and practices to the experienced irregularity of events, but do so whilst preserving the focus on constant conjunctions, and might consider this to be 'good science'. So, models might be constructed as closed systems that can express an isolated repeating constant conjunction. The model might require ideal assumptions (of a kind that do not just hold other effects at bay but are actually impossible or false) that separate out the conjunction. Caveats may be applied to the model - it is a partial or limited expression that may or may not have real-world significance as it is - whilst the model is still used as the basis of understanding and further insight.

One might also develop more or less sophisticated approaches to constant conjunctions. Exogeneity may be allowed for, and the constant conjunction may be between several xs and a y or a range of possible ys, and this may be expressed stochastically. But consider what is being done here. Allowing for exogeneity is to model distortions and deviations for the constant conjunction, whilst preserving the central and perpetual significance of the constant conjunction. Stochastics meanwhile produce patterned variation rather than genuine irregularity or novelty; that is, stochastics are typically limited to prior definable separated causal links and to changes of state rather than open-ended transformations of relations and things. ${ }^{6}$

Again, one is preserving the focus on the 'whenever $\mathrm{x}$ then $\mathrm{y}$ ' and so one is perpetuating the fundamental problem of the epistemic fallacy, which distorts everything else. Moreover, in neither case is closure genuinely put aside, it is merely adjusted. The important underlying and general point is that a process of preservation of the approach to knowledge claims can dominate the development of a field because one does not stop to reconsider the original problem, and it is here that ontology is useful or insightful. From the perspective of ontology, rather than seeking to preserve the nature of a knowledge claim as a primary (if sometimes tacit) goal, one ought first to ask: what seems to be an appropriate conceptualization of reality about which knowledge claims can then be made? It is from the ontological focus that the concept of an open system then follows.

Reality does not seem to typically be one of strict regularity expressed in events; rather, it seems to be one in which we experience relatively stable but also irregular events. The failures of a constant conjunction approach based on closed systems then allow us to infer that reality may be more adequately represented by an ontology of open systems. An open system is one in which there are many generative mechanisms and thus the continual possibility that similar events are brought about through different mixes, and where there is also the converse possibility that variations in events may occur because of different mixes. An open system is one that allows for the possibility of both relative stability in events but also degrees of irregularity; it allows for the possibility of complex causation; it recognizes the possibility of basic uncertainty of outcomes; and the possibility that there can be qualitative changes to aspects of the system that then result in transformations of that system, so there can be change within and change from a given system 
to something else. An open system is thus potentially 'dynamic', and it may then also be emergent and a source of further emergence. ${ }^{7}$ It is, as such, radically different in conception from a closed system concept expressed through a constant conjunction focus.

A constant conjunction focus cannot allow for irregularity and thus can only approximate or track relative stability in a highly conditioned way, and then breaks down, must be reconceived, or adjusted, or becomes irrelevant under circumstances of irregularity. An open system approach, meanwhile, can accommodate the situations in which a constant conjunction approach may be relevant, but goes beyond this. An open system is still recognizably a 'system' because it exhibits organization whose characteristics and complex mixes (including in terms of stratification) can be explored. For the concept of an open system to be meaningful as a 'system' there must be something substantively connected and at least relatively enduring to explore and thus to use as the focus for explanatory endeavour; openness does not simply mean absence of explicable aspects - there may be degrees of openness, but a fully open system would be conceptually incoherent since by definition it would not be a system. ${ }^{8}$ Thereafter, what makes a particular system 'open' depends on the nature of the significant powers of its aspects; that is, what are the sources of its generative mechanisms and how do these arise and how do they manifest in events? This brings us more specifically to social ontology and the issue of social science.

\section{Agency, Structure, and Historical Process (the Transformational Model of Social Activity, and Morphogenesis)}

Starting from issues arising in terms of natural science may give the impression that critical realism simply transposes natural science issues into the context of society and for social science in some unadulterated fashion. This is not the case. Rather, it was in response to problems created by such a transposition that critical realism (and others with a family resemblance) developed a social ontology. More specifically, a critique in terms of problems of realism was manifestly relevant for the social sciences because of the transmission of characteristics of positivism to the social sciences and because of some of the response to this. The adoption by the social sciences of a positivist approach to knowledge created a focus on identifying constant conjunctions in different aspects of society and a concomitant and overwhelming focus on methods that identified, expressed, or tested constant conjunctions. Positivism led to a particular focus on quantity and measurement, subject to forms of hypothesis testing, as the gold standard of social science research. ${ }^{9}$ Positivism in the social sciences thus arrogated status and prestige from the natural sciences, but did so based on positivism's already existing errors in representing the natural sciences: an epistemic fallacy leading to a focus on atomistic relations as isolated constant conjunctions in events and indicative of a closed system. This was not the application of science to society to create social science, but rather scientism. Some responses to this approach, however, emphasized that society was not explicable in terms of the positivist project. Humans, unlike electrons, think and change their mind; they have an interior world that affects their exterior activity and one must understand this interior world to appreciate and explore social significance. This then led to the counterposing of forms of phenomenology, hermeneutics, and social construction to positivism. ${ }^{10}$

From a critical realist position, and considering the social sciences in general, the 
rejection of positivism by hermeneutics and similar positions had created a false split between natural science and the exploration of society. The hermeneutic critique conflated positivism and natural science, as though positivism was an adequate account of nature but inappropriate for society; in so doing it failed to consider what was both ontologically similar and different about the rest of reality and the human being and their situation. From a critical realist position this is about the nature of generative mechanisms and powers of entities; that is, the emergent and stratified elements of social reality, which make it a distinct area of study. Here, the core ontological concepts were developed in terms of recognized problems of methodological individualism and structuralism, voluntarism and determinism, freedom and necessity, or what is typically termed the agentstructure problem, rooted in Marx's well-known statement in the 'Eighteenth Brumaire' that 'Men make their own history, but they do not make it just as they please; they do not make it under circumstances chosen by themselves; but under circumstances directly encountered, given and transmitted from the past' (Marx 1852 [1950], p. 225).

According to critical realism, agents and structures are analytically distinct. Structure consists in developed forms (expressed materially, technologically, organizationally, and so forth) infused with primarily concept-dependent social relations, which provide material (in the broadly Aristotelian sense of contextual) causation that serves to influence what seems possible, what is done, how it is done, and under what general institutional rubrics. Agents occupy roles or positions in social relations and draw upon them to engage in particular activity, creating effective causation. Agents are intelligent interpretive beings, and have reasons for acting as they do, of which they may in any particular instance be more or less conscious, depending on how they are socialized and the degree to which reflexivity is applied to any given situation. Agents act under multiple influences and may have a wide range of reasons for acting. As such, events are not typically a result of a constant conjunction situation, and outcomes can be highly variable. At the same time, there can often be a general stability to contexts and outcomes, social structure often develops to achieve particular goals and ensure some security in terms of those goals, so generalized reproduction of structure through the activity of agents is not untypical (moreover, choice can be constrained and sometimes highly limited because social relations are also power relations: in capitalism one typically works for wages to survive and cannot refuse all employment). However, structural reproduction is not typically the reason for the activity of the agent (one does not work in order to reproduce the corporation or use money in order to reproduce the medium of exchange or the banking system, but one must have a concept of money as an institutional form for both). Reproduction, then, can be an everyday unintended consequence of activity, but equally changes brought about by activity (including the reflexivity of the human) can transform structure, and this could be gradual or rapid. Bhaskar (1979), for example, originally refers to the social ontology as the transformational model of social activity (TMSA), in which the individual is socialized but then also acts back to reproduce or transform the conditions of that socialization (see Figure 1.1).

The sociologist Margaret Archer $(1995,2000,2003)$ then provides an important additional point of emphasis for this social ontology. ${ }^{11}$ Archer emphasizes the significance of time (see also Patomaki 2011). The process is one of interaction, and this happens in time and in recognizable phases. When agents do (or fail to do) something they do so in the context of the products of previous cycles of activity, which provide a context of 

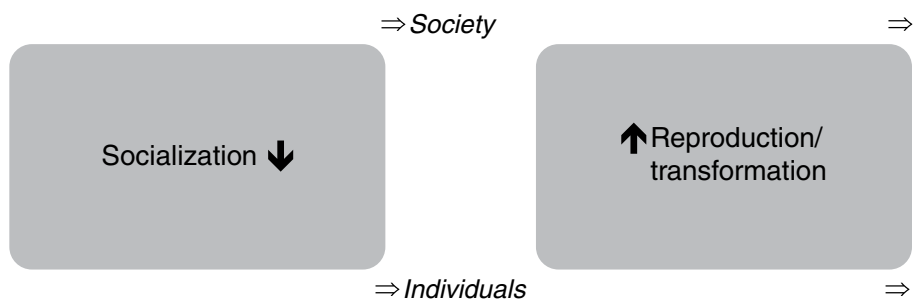

\section{Figure 1.1 Transformational model of social activity}

structural conditioning in terms of which the activity occurs $\left(T^{1}\right)$. Structure is deemed to be real because it has distinct emergent properties: it is a means by which things are conceived and done, and thus both constrains and enables agency in specific ways. ${ }^{12}$ These conditions remain relevant through interactions engaged by agents ( $T^{2}$ to $T^{3}$ ) and the agent is deemed to be distinct from structure insofar as they also have emergent properties (moving, doing, thinking, deliberating, believing, intending, loving, cooperating, and so forth) that are applied to the conditions of structure. The product over the time of interaction may then be relative reproduction of structure (and also, by degree, of the agent's sense of self in different contexts), that is, 'morphostatis'; or some more fundamental transformation, that is, 'morphogenesis' (in either case there is a $T^{4}$ that can then become the source of another cycle) (Figure 1.2). What Archer brings to the fore here is that the separation of agency and structure is a necessary conceptualization because each has different emergent properties, and because if the separation is not acknowledged,

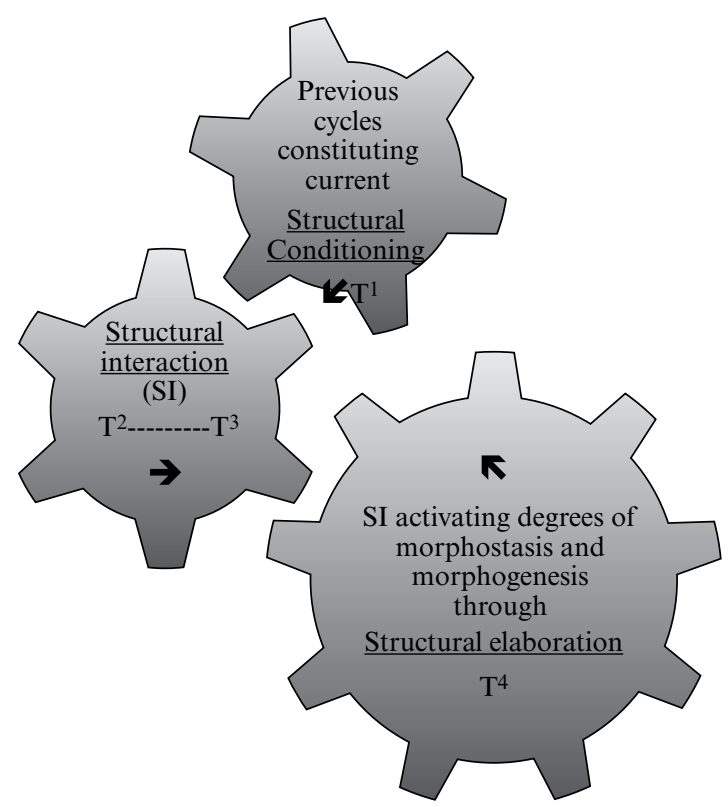

Figure 1.2 Archer's temporal cycles: morphostasis/morphogenesis 


\section{Handbook of research methods and applications in heterodox economics}

then it becomes difficult to explore interactions as occurrences or events in time (that is, as subject to process). The ontology also emphasizes the relative duration of the grounds of events and emphasizes that the grounds are historical (extending backwards in a significant sense) as well as ongoing.

The specific generative mechanisms of structure and agency can then be explored, in terms of different geographies and over different periods. This follows from the historical nature of processes: they need not be universal or uniform in space and time. Open systems can be explored at different scales in terms of different aspects. ${ }^{13}$ It is thus possible to have many different varieties of investigation of given social reality. An economist, therefore, is one who studies the economy as an aspect of a broader social reality and can do so by investigating different aspects of the economy in a variety of ways, based on different motivating questions and foci.

\section{Critical Realist Social Ontology and Economics}

It is important to emphasize at this point that critical realism is a general social ontology and not a school of thought in economics. It is not intended to be a replacement for groups of substantive theorizations that seek to explain and explore aspects of an economy. There is no critical realist economics in this sense. Critical realism remains an under-labouring approach in the sense set out in section 1.1 regarding social ontology. It has a variety of proponents with diverse interests in theory (see Fleetwood 1999; Lewis 2004). Its most well-known long-standing proponent is Tony Lawson (see 1997, 2003), a founding member of the Cambridge Social Ontology Group, which has served as a place for the discussion and dissemination of social ontology in economics for many years. ${ }^{14}$ Nuno Martins (2014) has subsequently made the case that the work in social ontology is part of a broader 'Cambridge tradition', encompassing Keynes, Sraffa, Robinson, Sen, and others. The core of the social ontology articulated by Lawson and others is that an economy is an aspect of a social reality that exhibits emergence and is characteristically a dynamic open system of a historical-process form in which change is cumulative through social interaction. Whilst this is not a substantive theory of an economy for economists it does have implications for economic theorization.

One of the under-labouring claims made by Lawson is that heterodox economists (see Lee 2009) are united by a common, and sometimes only implicit, open systems ontology (Lawson 2006). According to Lawson it is this, expressed in different ways, which differentiates heterodoxy from mainstream economics. Mainstream economics is dominated by approaches whose underlying ontology is based on deductivism in which constant conjunctions (including through stochastics) are the focus. Theory and practice are thus built around closed systems and use ideal assumptions and ahistorical categories (that deform real-world investigations, including any subsequent approach to structure in terms of history and institutions) to facilitate closure. It is because of this basic mismatch with social reality that the mainstream exhibits persistent explanatory failure, a failure that becomes more noticeable and controversial during periods of significant change. ${ }^{15}$

Heterodox approaches, by contrast, focus on different aspects of open systems. ${ }^{16}$ So, classical political economists focus on the conditions of reproduction of the economic surplus, including the significance of its distribution; old institutionalists might focus on the constraining and enabling dynamics of institution formation and their consequences; 
feminist economists might focus on patriarchy; Marxists on class relations in the reproduction and development of capitalism; Keynesians and post-Keynesians on the vulnerabilities in relations of production, consumption, investment, and employment; finance system economists on the creation of money in a fiat system dominated by the creditdebt powers of private banking and subject to a complex institutional web of financialization; eco-economists might focus on the complex relations between the economy and the sustaining environment in which it is embedded; and so forth.

Here, the claim is that underlying aspects of social ontology unite heterodox diversity, just as they differentiate heterodoxy from the mainstream. This then implies a form of relativism for heterodox knowledge claims, in the sense that there are many ways to adequately investigate an economy. This, however, is subject to a constructive pluralism (for issues see, for example, Dow 2000, 2008). Any theory or approach may be improved based on continued research and based on the primary tenet that the world can be more or less adequately investigated. It may also be that any given theory or approach is superseded because more adequate ways of investigating its key issues are developed or because the world simply changes in its significant aspects (for example, new forms of emergence). For improvement or supersession of theory to occur effectively then diversity within economics needs to be more than simply tolerance of different positions: it ought also to be critically engaged across positions. So, there is a curious tension in the development of economics as knowledge, from a heterodox point of view. Social ontology provides a domain for dialogue and critique, diversity within heterodoxy provides many potentially adequate ways of investigating an economy, all approaches may become more adequate in terms of investigating some aspect of an economy as social reality (and may also be superseded), and one way in which each might develop is through evidence, critique, and dialogue provided by other branches of heterodoxy. This process involves also further conceptual development and critique of issues in social ontology, including of critical realism, since ontology is theory and not reality (see, e.g., Boylan and O'Gorman 1995; Brown 2007; Chick and Dow 2005; Dow 2004; Fullbrook 2009; Milonakis and Fine 2009; Mohun and Veneziani 2012; J. Morgan 2012; Nielsen and Morgan 2006).

Constructive pluralism is then also a basis by which a problem of judgemental relativism, a simple 'anything goes', is rejected. Instead, there is a loose normative commitment to a form of 'judgemental rationality': the active pursuit of the possibility that competing knowledge claims can be reasoned out in terms of their justifications, and can then perhaps also be moved beyond. In practice such judgemental rationality is an open-ended process, rather than something that can be considered complete. It requires a community of scholars who do more than pay lip service to the possibility that others may identify errors in their work and that the world may simply confound their previous best efforts. The commitment is simple to state but it would be simplistic to suggest that the commitment is easily realized. One of the important insights that social ontology also brings to economics is that economics is knowledge as a social product and the economics discipline is also a system of sorts.

A closed system ontology is not just expressed in the theory and practice of mainstream economics; it is reproduced through the activity of mainstream economists. This has had consequences for the marginalization of heterodox economics (e.g., Lee et al. 2013). It has also meant that one can explore the way in which the mainstream has historically developed. There are many ways to do this and not all of them are about ontology 
(see Mohun and Veneziani 2012), but one can note the way that the initial recognition that economics was a subject with great potential in terms of a focus on definable quantities and measurements (trade, prices, outputs, costs, employment, and so forth) made it highly conducive to translation into a mathematically oriented subject (see Lawson 2003, Ch. 10). One might consider this important because the mainstream has translated the use of quantities into the dominance of quantification. This is exhibited in terms of methods (an overwhelming focus on econometrics), the expression of theory (typically stated in symbolic form, and developed as mathematical proofs of theorems), and also the presumption that model building, testing, and application are core to the economist's skill set (so attempts to incorporate structures, institutions, processes, differentials, and so on must be made compatible with this core).

The key point here is that the reproduction of this dominance of quantification serves to reproduce a closed system ontology and so one might also note that the mainstream, though it may exhibit some changes, is also conformist. It cannot easily be constructively pluralist in a way that is also genuinely committed to judgemental rationality, and this is not an additional point to the argument for ontology in economics, it is one that can be made through thinking in terms of ontology - if one considers economics as a knowledge product. This brings us to the issue of methodology and methods, following from matters of social ontology.

\section{Economics, Methodology, and Methods}

Heterodox economics is not simply an attempt to defend and advocate long-standing schools of thought and theorizations. It is a living body of inquiry that draws critically on existing schools and theorizations, but also develops others. Social reality is only relatively enduring in its forms and so new problems and issues arise and old ones wane. One way that mainstream economics has dealt with this problem is by emptying itself of substantive content, becoming a set of idealized ahistorical universals, reductively applicable everywhere but genuinely relevant nowhere: the rational actor, the game player, the utility maximizer under conditions of constraint, and so forth. This, and the transferability of model building, has provided an important basis for economics imperialism (see M. Morgan 2012; Fine and Milonakis 2009). The heterodox approach is quite different: rather than the ontology undermining any attempt to be continually relevant, the ontology recognizes that relevance is about engaging with a changing and multifaceted world and requires both that theory encompasses change and that theory can also be restructured around a changing world. This is extremely difficult to do if one starts from a closed system ontology. An open system ontology provides a more consistent point of departure for methodology and for methods (see Danermark et al. 2002; Carter and New 2004).

Methodology is often, but should not be, confused or conflated with research methods (see Frauley and Pearce 2007, p.9; Olsen and Morgan 2005; Sayer 1992). Methodology is an overall research strategy. It is imbued with a research perspective that shapes how the research process is understood and how different methods are used, and the sense that is made of their use. A research method is a given technique of data collection and processing. Methods may be qualitative or quantitative, or involve stages such as quantitative processing of qualitative data (Olsen 2012). Methodologies 
in practice may involve the use of only one method or selection from only one type of method (a restricted mix) or may involve different types of methods (a broad mix). In standard research method texts methodology is familiarly stated in inductive or deductive terms and typically subject to broadly positivist understandings of how knowledge is acquired and processed (such as hypothesis testing of large data sets) or as subject to phenomenological understandings of how knowledge is acquired and processed (such as detailed interpretive explorations of case studies and interviews, or significant forms of participant observation).

Heterodoxy, as an empirically oriented endeavour, is not restricted to standard methodology and selection of methods (see Downward 2003). It is possible that one simply absorbs the general ontology and uses it intuitively as the basis of research, producing work rooted in open systems (e.g., Morgan 2009). Equally, one might develop an explicit methodology and justification of methods. A heterodox approach to research methods is diverse, different methods can be used and multiple methods can be used. This, however, is not arbitrary or random - the throwing of methods at data and the compiling and processing of data through any available method (see, e.g., Byrne 2013). It is a structured process of iterative engagement, partly reliant on the growing competency and insight of the researcher and a community of researchers. This can involve exploratory and experimental use of methods in particular circumstances that can then be refined or abandoned. The point of departure, in the broadest sense, is the nature of the empirical problem, conceived in terms of an open systems ontology. This is not empiricism in disguise but rather recognition that there are real-world problems to be addressed by theory and through investigation. The ultimate guide is the explanatory success provided by the use of methods and based on some given methodology. As a matter of consistency, from an open systems point of view, there can be no a priori exclusion of methods, though there can be the gradual development of reliance upon particular methods in given circumstances based on the insights they provide. This, however, is a phased a posteriori process.

The main restriction on methodology is whether in practice it provides for explanatory success. Tentatively, this involves the anticipation that the methodology is appropriate as a means of investigating and building theory in regard of an open systems social reality with emergent features, relatively enduring structures, and ways of proceeding by conscious agents, and which exhibits historical and geographical diversity. Research must be in a sense historical, involve an understanding of agents, and of persons, of the institutions in which they are immersed, and of the facilitating and constraining role of structures of social relations and structures of such structures. It must be sensitive to the complexity of causation; that relative stability may disguise some quantitative and qualitative changes that are cumulatively changing the way in which events are currently unfolding and relative reproduction is occurring (the dynamics of depth realism in the context of social reality).

Any or all of the above could become a focus or emphasis for research, and do so at different scales. One might, for example, focus on types of individual within the household, the household, the consumer, the firm, the supply chain, a market, markets, the state in its various roles, the employee, labour, trade, the economic sector, the economy, or capitalism. One might be exploring dynamics or focusing on a particular phenomenon (some -ism or concept dependency such as money) or narrowing down to a particular 
kind of agent or form of agency, or of significant identity, but always with a sense of the broader context. Given the issue of potential complexity in open systems, an important general point here is the need to identify some cut-off point to delineate the research without damaging the potential insights of the research. This implies a need to justify the limits of the focus and also implies the potential use of abstraction, carefully distinguished from idealization (see Sayer 1992).

The basic point here is that one adapts and develops research to the nature of the problem under investigation and to the type of research question one is asking in terms of that investigation. As a general point this hardly seems controversial. It seems no more a matter of common sense than the statement in section 1.1 that any science, including a social science such as economics, ought to be about reality, the nature of reality ought to make a difference to how we study it and what we then claim about it as a form of knowledge.

Essentially, the basic point is simply a methodological specification of this statement. It may, therefore, seem uncontroversial, but considered in the context of economics it is extremely significant. Mainstream economics is heavily reliant on a narrow range of methods, and many economics departments do not teach philosophy and methodology as part of research training or introduce the postgraduate to a range of possible methods particularly qualitative methods and more innovative ways of processing data (NVivo, QCA, network analysis, and so on). ${ }^{17}$ As such, they simply reproduce a focus on a narrow range of technical skills that then become the basis by which research is typically done, because researchers are unaware of the alternatives or lack the competency in them. They become by default methods a priori and thus irrespective of other possibilities, rather than arise and are renewed a posteriori. So one might note that many economists are simply incapable of approaching the basic point above in an open and creative way.

Heterodoxy, by contrast, is receptive to methodological range and to mixed methods because of, and insofar as it takes seriously, an open systems ontology. Various approaches to methodology have been suggested that go beyond the inductive-deductive and positivist-phenomenological splits. These have included abduction, retroduction and retrodiction, contrast explanation and grounded theory.

Abduction, following Peirce, is a form of inference, usually distinguished from deduction and induction. As a form of reasoning with a logical structure the key difference is that deduction is based on premises from which the conclusions then necessarily follow, while induction is based on premises that are then exceeded by the conclusions, but where the conclusions are not stated as an explanation from the premises, and abduction is a form in which the conclusions also exceed the premises, but where an inference is also made to the best explanation of the situation under scrutiny. In terms of research the difference is usually stated in terms of the context of theory: deduction starts from theory, induction builds theory (but does so based on frequencies), and abduction focuses on a range of explanations included as theory, and considers them in some context of justification for elimination. Abduction is less 'rigorous' in the formal sense of a logical construct and in the range of possible ways one might distinguish between explanations. It is, however, a closer fit with the complexity of an open system, since it embraces the possibility of irregularity and of many forms of potential evidence, and thus also the use of many different methods, as deemed appropriate. 
Retroduction and retrodiction are often discussed in the same terms as abduction, but starting from an explicit open systems ontology. They involve the identification of some generative mechanism and an attempt to account for the form of that generative mechanism, drawing on a range of possible formulations that extend to a role for metaphor and analogy (the abstract phase of retroduction), but which also then involve empirical investigation subject to some devised tests of the plausibility of the account; an iterative process of investigation (or retrodiction) from which some ways of viewing the problem are eliminated (see Bhaskar 1979, p. 15).

Contrast explanation provides another alternative strategy that starts explicitly from an open systems perspective (Lawson 2003, pp. 86-109). Contrast explanation starts from how a research focus arises or is motivated: the economist observes an unexpected or unusual event or series of events, and that may mean an unexpected degree of continuity or stability, or some degree of change. The capacity to make such an observation implies a competent economist immersed in real-world problems, a degree of acquired and oriented expertise, and the observation invites the question 'Why x rather than y?', where the contrast is to the possibilities that did not arise or were not realized in some given time and place. This can then be rooted in terms of contrasts with what has occurred under apparently similar circumstances in the past or some comparable location, providing some degree of specification for understanding and explaining the basis of events as they have occurred, and could have occurred, and also, tentatively, for what may occur (since one may be identifying underlying changes to the reproduction of what appears to currently be expressed as relative stability; for example, Morgan 2013). Again, this is an approach with a wide degree of latitude.

Grounded theory is an attempt to provide a more programmatic or specified form of open systems investigation and is set out in Chapter 2 of this Handbook (see also Lee 2012). The key point to take forward here is that all the stated forms of approaches to methodology are compatible with or are located within an open systems ontology and allow for a more creative use of mixed methods. Insofar as they are oriented towards realism (in the philosophical-empirical sense) they also allow for the possibility of triangulation (Olsen 2004).

\subsection{CONCLUSION}

Social ontology provides important under-labouring functions for economics. It provides a relevant domain of argument in terms of which continued critique of the realism of economics can occur. It provides a domain in which substantive ontologies can be constructed in terms of problem sets arising in social science and in economics specifically. One might argue that heterodoxy is united by a common open systems ontology and is also distinguished from mainstream economics by this ontology. However, one needs to be careful in regard of what is claimed for and from ontology. Ontology is still, in a general sense, theory, and so must also be treated with some degree of scepticism and critique. It is also not a replacement for substantive theory in economics; it is not itself a school of thought in economics. It does have implications for methodology and for methods. Those implications, however, are positive - an opening up - rather than negative, since the basic point is that economics can legitimately be more creative in its methodology and broader 
based in its use of methods. This is illustrated throughout this book. As a final point I would also note that the claim regarding methodology and methods leaves a major point of controversy untouched. Mainstream economics is often, as it is here, criticized for its formalism and for its overwhelming reliance on quantitative methods, and especially the use of econometrics. This raises the issue of whether quantitative methods are still relevant if one rejects the mainstream approach. There is a tendency to assume that critical realists in particular reject quantitative methods, but this is not the case. There is some degree of disagreement regarding the relative use of them, rather than a rejection of them (see, e.g., Lawson 2003; Downward 2003; Fullbrook 2009). As a matter of ontological consistency one cannot reject them a priori. Lawson, who is most closely associated with scepticism regarding formalism and econometrics, states:

I hope by now the highly conditional nature of my criticism is apparent. It is not, and has never been, my intention to oppose the use of formalistic methods in themselves. My primary opposition, rather, is to the manner in which they are everywhere imposed, to the insistence on their being almost universally wielded, irrespective of, and prior to, considerations of explanatory relevance, and in the face of repeated failures. (Lawson 2003, p. xix)

There are two underlying issues here. First, whether the way in which quantitative methods are used and understood allows methods that are based on closed systems to be insightful in terms of a dynamic open system. Put another way: does recognition in terms of an ontological critique facilitate the continued use of methods - are they then contributions to an explanatory investigation? Second, whether all quantitative methods assume or rely on or identify, express, and test some form of constant conjunction as a closed system. If not, are they subject to the ontological critique? Again, different contributors to this text have different opinions on this. I would just suggest here that the very fact that debate is occurring in regard of this is a major advance for economics, since it is, as Lawson suggests, the non-reflexive default to given quantitative methods that provides one of the major grounds for critique of economics. Much of the rest of this book is taken up with related issues and demonstrations.

\section{NOTES}

* Thanks to Fred Lee and Tony Lawson for comments on this chapter.

1. For example, Roy Bhaskar uses the term 'transcendental realism' in A Realist Theory of Science (1975), which addresses issues surrounding the philosophy of science; the term 'critical naturalism' in The Possibility of Naturalism (1979), which addresses issues in the social sciences; and the catch-all term 'critical realism' in the later collection of essays Reclaiming Reality (1989). Bhaskar also has his own taxonomy of phases of critical realism, though that need not concern us here. In general, many proponents of similar positions use the term 'scientific realism' (though there is of course also a degree of differentiation and critical dialogue between specific positions).

2. One does not need to be a follower of Nietzsche to acknowledge that often 'Convictions are more dangerous enemies of truth than are lies' (Nietzsche 1995, Ch. 9,\#483, p. 264).

3. The following material is condensed and does not follow the order of argument in the texts from which it is drawn (Archer 1995; Bhaskar 1975, 1979, 1989; Collier 1994; Lawson 1997, 2003; Morgan 2007; Sayer 1984, 2000). It is constructed for simplicity. Note also that much of the development of similar insight regarding social science began around the same time: Russel Keat, John Urry, Ted Benton, William Outhwaite, Tony Lawson, and others, all were responding to a general problem set created by contemporary developments. 
4. Note, the table has heuristic value if one is unfamiliar with this subject but it is also an oversimplification. One might argue that typically mechanisms are actualized potentials; so they are as much actual as real, and in this sense so are the powers or potentials themselves.

5. The opposed error would be to ascribe the powers or potentials solely to the humans who induced the events in the laboratory; a strong form of social construction associated with the work of Woolgar and Latour.

6. Though complexity models, fuzzy set approaches and other methods involve further issues.

7. Concomitantly systems might be conceived also as nested, overlapping, and/or interactive.

8. The more difficult conceptual and empirical issue is: what is the boundary of a system?

9. The original meaning of positivism according to Comte was the gradual movement in knowledge acquisition from the natural sciences to the social, as scientific principles of investigation took root, and superstition and mysticism were banished by the application of reason and evidence. The process turned out somewhat differently.

10. And later also post-structuralism and postmodernism (see Sayer 2000), and more latterly, actor network theory (ANT).

11. Archer also adds an additional significant emphasis. There is more to the agent than simply a role or position since the agent is also a person, so the range of activity engaged through the role can be complex, based on how the agent fulfils their role but also based on further aspects of the person (personal psychology, projects, and so on). If one fails to recognize this then the human tacitly reduces to an oversocialized product of a series of positions in society.

12. Archer distinguishes structural and cultural emergent properties but there is insufficient space here for a full discussion.

13. So one might, for example, differentiate the internal social relations; that is, those that are 'necessary' to an identified form in the sense that the relation could not be what it is without them - wage labourer and capital ownership - from those that are external or not necessary to the form; and then explore how the form develops historically.

14. The course of critique and debate in economics has been somewhat different than in other areas such as sociology. Significant recognition and debate has been mainly in terms of philosophical theories (including ontologies). An immanent critique of various conceptions has led to growing support for critical realism, but also some misunderstanding. There is then also the question of moving from philosophical to scientific ontology (see Lawson 2014).

15. The ontology also acknowledges that open systems when viewed in the aggregate can be more or less integrated or cohesive in their structural aspects. This is a point also explored by regulation school political economists, such as Bob Jessop, based on a 'strategic-relational' approach influenced by critical realism, and also Poulantzas. In economics it is a matter of current concern in regard of the global financial crisis.

16. The following are not intended as discrete or complete categories.

17. NVivo is computer software for qualitative data analysis. QCA refers to qualitative data analysis, a series of systems for combining variables in data sets to support logical inference regarding the data. Network analysis refers to a set of software packages that allow the research to build up a visual representation of the direction, strength, and breaks in key relations within and between phenomena, often organizations. For use of these three see subsequent chapters in this volume.

\section{REFERENCES}

Archer, Margaret (1995), Realist Social Theory: The Morphogenetic Approach, Cambridge: Cambridge University Press.

Archer, Margaret (2000), Being Human: The Problem of Agency, Cambridge: Cambridge University Press.

Archer, Margaret (2003), Structure, Agency and the Internal Conversation, Cambridge: Cambridge University Press.

Bhaskar, R.A. (1975), A Realist Theory of Science, London: Verso.

Bhaskar, R.A. (1979), The Possibility of Naturalism, Brighton: Harvester.

Bhaskar, R.A. (1989), Reclaiming Reality: A Critical Introduction to Contemporary Philosophy, London: Verso.

Boylan, T. and P. O'Gorman (1995), Beyond Rhetoric and Realism in Economics: Towards a Reformulation of Economic Methodology, London: Routledge.

Brown, A. (2007), 'Reorienting critical realism: a system-wide perspective on the capitalist economy', Journal of Economic Methodology, 14 (4), 499-519.

Byrne, D. (2013), 'Evaluating complex social interventions in a complex world', Evaluation, 19 (3), $217-28$. 


\section{Handbook of research methods and applications in heterodox economics}

Carter, B. and C. New (eds) (2004), Making Realism Work: Realist Social Theory and Empirical Research, London: Routledge.

Chick, V. and S. Dow (2005), 'The meaning of open systems', Journal of Economic Methodology, 12 (3), $363-81$.

Collier, A. (1994), Critical Realism: An Introduction to Roy Bhaskar's Philosophy, London: Verso.

Danermark, B., M. Ekstrom, L. Jakobsen, and J. Karlsson (2002), Explaining Society: Critical Realism in the Social Sciences, London: Routledge.

Dow, S. (2000), 'Prospects for progress in heterodox economics', Journal of the History of Economic Thought, 22 (2), 157-70.

Dow, S. (2004), 'Reorienting economics: some epistemological issues', Journal of Economic Methodology, 11 (3), 307-12.

Dow, S. (2008), 'Plurality in orthodox and heterodox economics', Journal of Philosophical Economics, 1 (2), 73-96.

Downward, P. (ed.) (2003), Applied Economics and the Critical Realist Critique, London: Routledge.

Fine, B. and D. Milonakis (2009), From Economics Imperialism to Freakonomics, London: Routledge.

Fleetwood, S. (ed.) (1999), Critical Realism in Economics: Development and Debate, London: Routledge.

Frauley, J. and F. Pearce (eds) (2007), Critical Realism and the Social Sciences: Heterodox Elaborations, Toronto: University of Toronto Press.

Fullbrook, E. (ed.) (2009), Ontology and Economics: Tony Lawson and His Critics, London, UK and New York, USA: Routledge.

Harré, R. and E. Madden (1976), Causal Powers, Oxford: Blackwell.

Lawson, T. (1997), Economics and Reality, London: Routledge.

Lawson, T. (2003), Reorienting Economics, London: Routledge.

Lawson, T. (2006), 'The nature of heterodox economics', Cambridge Journal of Economics, 30 (4), $483-505$.

Lawson, T. (2014), 'A conception of social ontology', in Stephen Pratten (ed.), Social Ontology and Modern Economics, London: Routledge, pp. 19-52.

Lee, Frederic S. (2009), A History of Heterodox Economics: Challenging the Mainstream in the Twentieth Century, London: Routledge.

Lee, Frederic S. (2012), 'Critical realism, grounded theory and theory construction in heterodox economics', MPRA Paper: 40341.

Lee, Frederic S., X. Pham, and G. Gu (2013), 'The UK Research Assessment Exercise and the narrowing of UK economics', Cambridge Journal of Economics, 37 (4), 693-717.

Lewis, P. (ed.) (2004), Transforming Economics: Perspectives on the Critical Realist Project, London: Routledge.

Martins, N. (2014), The Cambridge Revival of Political Economy, London: Routledge.

Marx, K. (1852 [1950]), 'The eighteenth Brumaire of Louis Bonaparte', in K. Marx and F. Engels (1950), Selected Works Volume 1, London: Lawrence \& Wishart.

Milonakis, D. and B. Fine (2009), From Political Economy to Economics, London: Routledge.

Mohun, S. and R. Veneziani (2012), 'Reorienting economics', Philosophy of the Social Sciences, 42 (1), 126-45.

Morgan, J. (2007), 'Critical realism', in G. Ritzer (ed.), The Blackwell Encyclopaedia of Sociology: Vol II, Oxford: Blackwell, pp. 870-73.

Morgan, J. (2009), Private Equity Finance: Rise and Repercussions, Basingstoke: Palgrave Macmillan.

Morgan, J. (2012), 'Economics critique: framing procedures and Lawson's realism in economics', Journal of Critical Realism, 11 (1), 94-125.

Morgan, J. (2013), 'Forward-looking contrast explanation illustrated using the Great Moderation', Cambridge Journal of Economics, 37 (4), 737-58.

Morgan, M. (2012), The World in the Model, Cambridge: Cambridge University Press.

Neilsen, P. and J. Morgan (2006), 'From mainstream economics to the boundaries of Marxism', Capital and Class, 89 (1), 91-120.

Nietszche, F. (1995), Human All Too Human, Stanford: Stanford University Press.

Olsen, W. (2004), 'Triangulation in social science research: qualitative and quantitative methods can really be mixed', in M. Holborn (ed.), Developments in Sociology, Ormskirk, UK: Causeway Press, pp. 103-21.

Olsen, W. (2012), Data Collection: Key Debates and Methods in Social Research, London: Sage.

Olsen, W. and J. Morgan (2005), 'A critical epistemology of analytical statistics: addressing the skeptical realist', Journal for the Theory of Social Behavior, 35 (3), 255-84.

Patomaki, H. (2011), 'On the complexities of time and temporality: implications for world history and global futures', Australian Journal of Politics and History, 57 (3), 339-52.

Sayer, A. (1984), Method in Social Science, London: Routledge.

Sayer, A. (1992), Method in Social Science: A Realist Approach, 2nd edn, London, UK and New York, USA: Routledge.

Sayer, A. (2000), Realism and Social Science, London: Sage. 